\title{
Monoclonal Antibody (5G6.4) against Ovarian Carcinoma Shows Inhibition of in Vitro Colony Formation ${ }^{1}$
}

\author{
Lorna Rodriguez-Rodriguez, M.D., ${ }^{*}$ Monica Liebert, Ph.D., $\dagger$ \\ Ronald Natale, M.D. $\ddagger$ and Richard Wahl, M.D. $\dagger$ \\ *Department of Obstetrics and Gynecology, Division of Gynecological Oncology, University of \\ Michigan; + Division of Nuclear Medicine, University of Michigan; and $\ddagger$ Department of \\ Medical Oncology, University of Michigan, Ann Arbor, Michigan 48109-0028
}

Received January 14, 1987

\begin{abstract}
Monoclonal antibodies (MAbs) have the potential for diagnosis and therapy of cancer. 5 G6.4 is a MAb of the IgG2a class which was produced by immunization of BALB/c mice with human ovarian carcinoma (Ov Ca) cells. To further characterize $5 \mathrm{G} 6.4$, its effect on cell growth was tested using a human Ov Ca cell line established in our laboratory. A clonogenic assay was set up in 48-well plates in a double agar system. The cells were plated and 5G6.4 was added at different concentrations. Control plates consisted of cells with media without MAb. Negative control plates were also prepared using the same concentrations of an isotype-matched antimelanoma MAb, 225.28s. Colony formation (CF) was reduced to $50 \%$ or less of control with increasing amounts of $5 \mathrm{G} 6.4$ up to $50 \mu \mathrm{g} / \mathrm{ml}$. Although CF was still depressed at concentrations above $50 \mu \mathrm{g} / \mathrm{ml}$, the inhibition did not follow a directly proportional line; instead, it followed a bell-shaped curve. Plates with the control MAb, 225.28s, did not show this response. Similar results were obtained with cells from malignant $\mathrm{Ov} \mathrm{Ca}$ ascites in the same clonogenic assay. Our study suggests that in the evaluation of the in vitro effect of $\mathrm{MAb}$ on growth, the concentration of $\mathrm{MAb}$ is crucial and may not show a linear response and that 5G6.4 may have a direct therapeutic effect by blocking the growth of $\mathrm{Ov}$ Ca cells. $5 \mathrm{G6} 6.4$ is presently under study for therapy in an animal model. @ 1987 Academic Press. Inc.
\end{abstract}

\section{INTRODUCTION}

Monoclonal antibodies (MAbs) have the potential for use in therapy of cancers $[1,2]$ and have been used in some clinical trials in humans [3-8]. The results have been varied, and in some cases interaction of the host's immune system has appeared to be important in positive responses [3,9]. Studies have concentrated on complement activation or cell cooperation, such as antibody-dependent cellmediated cytotoxicity (ADCC; [10-12]). Yet another group of monoclonal antibodies is capable of directly inhibiting the growth of cells $[13,14]$.

We have begun evaluation of a monoclonal antibody, 5G6.4, reactive with human ovarian carcinoma ( $\mathrm{Ov} \mathrm{Ca}$ ) cells. Unlike some MAbs to leukemia which

\footnotetext{
${ }^{1}$ Supported in part by PHS R01-CA40497-02, DHHS R01-CA40531-01, and DOE contract DEAC02-76EV02031.
} 
cause modulation or loss of antigen expression [15], the 5G6.4-defined antigen does not appear to modulate (Wahl and Liebert, unpublished). Radioiodinated 5G6.4 localizes well in subcutaneous human ovarian tumors in nude mice, with tumor:blood ratios of $5: 1$ to $10: 1[16,17]$. Although $5 \mathrm{G} 6.4$ does bind to some normal human tissues (skin and kidney) [16], its high expression on Ov Ca cells and good localization in human tumor-bearing nude mice suggest promise as an immunolocating or immunotherapeutic agent. In this study, we demonstrate antigen expression on $\mathrm{Ov} \mathrm{Ca}$ cells by flow cytometry and radiolabeled antibody binding.

To further evaluate the usefulness of 5G6.4 for immunotherapy, we tested its ability to block growth of these cells using an in vitro colony formation assay.

\section{MATERIALS AND METHODS}

Cell lines. The methods for initiation and maintenance of the cell line used in this study have been previously described [18]. Briefly, the cell line (MI OV) was maintained in RPMI 1640 media supplemented with $10 \%$ heat-inactivated fetal bovine serum, $1 \%$ nonessential amino acids, $100 \mathrm{IU}$ penicillin $/ \mathrm{ml}, 100 \mu \mathrm{g}$ streptomycin $/ \mathrm{ml}, 2 \mathrm{~m} M$ glutamine. The cells were grown in T-25 tissue culture flasks and kept in a $37^{\circ} \mathrm{C}$ incubator at a $5 \% \mathrm{CO}_{2}$ atmosphere.

Collection of cells. Malignant effusion from a patient of documented recurrent carcinoma was used to retest the assay with a fresh tumor. Three liters of ascitic fluid was centrifuged (1000 rpm for ten min). The cells (TA OV) were then resuspended in RPMI and an aliquot was counted in a hemocytometer with trypan blue to identify the viable cells. The cells were resuspended into an adequate volume of RPMI in order to get the predetermined cell density needed for the clonogenic assay.

Monoclonal antibodies. 5G6.4 is an IgG2a murine monoclonal antibody prepared by immunizing BALB/c mice with HTB77, a human ovarian carcinoma cell line. It is directed against an epithelial tumor-associated antigen, found on the basal layer of various epithelia, proximal tubules of the kidney, ovarian tumors and several other types of tumors [16]. 225.28s is a monoclonal antibody reactive with a high-molecular-weight chondroitin sulfate antigen found in melanoma cells [19]. It is of the IgG2a subclass. UPC-10 is a murine myeloma IgG2a protein. Purified UPC-10 was purchased from Litton Bionetics (Rockville, MD). Antibodies were purified by affinity chromatography on staphylococcal protein A columns [20]. Purified antibodies were sterilized by filtration through a $0.22 \mu \mathrm{m}$ filter (Millipore, Bedford, MA) and were dialyzed against RPMI without serum overnight at $4^{\circ} \mathrm{C}$ under sterile conditions. The protein concentration was checked using the Bradford protein assay [21] immediately before use.

Flow cytometry. Washed tissue-cultured cells were incubated with $5 \mathrm{G6} .4$ at $20 \mu \mathrm{g} / \mathrm{ml}$ in $2 \%$ bovine serum albumin in phosphate-buffered saline $(0.01 \mathrm{M}$ phosphate, $\mathrm{pH} 7.2,0.14 \mathrm{M} \mathrm{NaCl}$; BSA/PBS). Cells incubated in BSA/PBS without antibody were used as a control. The cells were incubated for $\mathbf{l} \mathrm{hr}$ on ice and washed three times with BSA/PBS. Then the cells were resuspended in $1 \mathrm{ml}$ of fluorescein isothiocyanate (FITC)-conjugated goat anti-mouse IgG (Cappel, Cochranville, PA) diluted $1 / 100$ in BSA/PBS and the mixture was incubated for $1 \mathrm{hr}$ on ice. The cells were washed three times with BSA/PBS and resuspended 


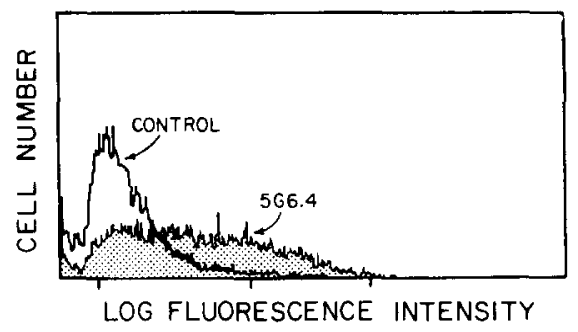

FIG. 1. Flow cytometry of MI Ov Ca cells without (no shading) or with (shaded) 5G6.4.

in $1 \mathrm{ml} \mathrm{BSA} / \mathrm{PBS}$. The fluorescence of cells was observed by fluorescence microscopy and analyzed using an Epics $\mathrm{C}$ flow cytometer (Coulter Diagnostics, Hialeah, FL).

Iodination. Antibodies were radiolabeled with ${ }^{125}$ I using "lodogen" as previously described [22]. Cell-binding assays were performed as previously described [23].

Soft agar clonogenic assay. An agar underlayer of $0.5 \%$ molten Bacto-agar (Difco I aboratories, Detroit, MI) was poured over the bottom of 48-well plates. After the agar solidified, the tumor cell-plating layer was poured over the top. Tumor cell-plating density was $2 \times 10^{3}$ cells/well, suspended in $0.3 \%$ molten Bacto-agar. The culture media added to both agar layers was RPMI on the bottom layer and the same media in which the cell lines grow on the top layer. After solidification of the agar the plates were incubated at $37^{\circ} \mathrm{C}$ with $5 \% \mathrm{CO}_{2}$ overnight. Twenty-four hours later, different concentrations of MAb diluted in RPMI were added to the top layer. The same volume of RPMI, without any antibody, was used as control. The cells were incubated again, and after 7-14 days, colonies were visible. Colonies were defined as aggregates of greater than 30 cells. Colony formation in control plates were compared to the number of colonies growing in the cultures with the different concentrations of MAb overlayers. Results of colony formation are given as percentage of control. All experiments were done in triplicate and the person reading the plates for colonies did not know which plates had antibody overlay nor their concentrations. MI OV cell line experiments were repeated three times and the fresh tumor (TA OV) experiment was performed once.

\section{RESULTS}

The reaction of 5G6.4 with MI Ca Ov cells is shown in Fig. 1 by flow cytometry. Cells incubated with an equal concentration of an isotype-matched control antibody (UPC-10) showed fluorescence intensity similar to cells incubated without antibody (data not shown). In the beginning of these experiments, 225.28s was used as a control antibody because the high-molecular-weight chondroitin sulfate antigen was thought not to be expressed by Ov Ca cells. In the course of these experiments, the 225.28s was shown to bind to Ov Ca cells by immunofluorescence microscopy. In a binding assay using radioiodinated antibodies, Ov Ca cells bound 3.5 times more 5G6.4 than 225.28s (data not shown). 225.28s has been reported to have an in vitro effect on melanoma cell growth due to ADCC [12]. In our hands, its 


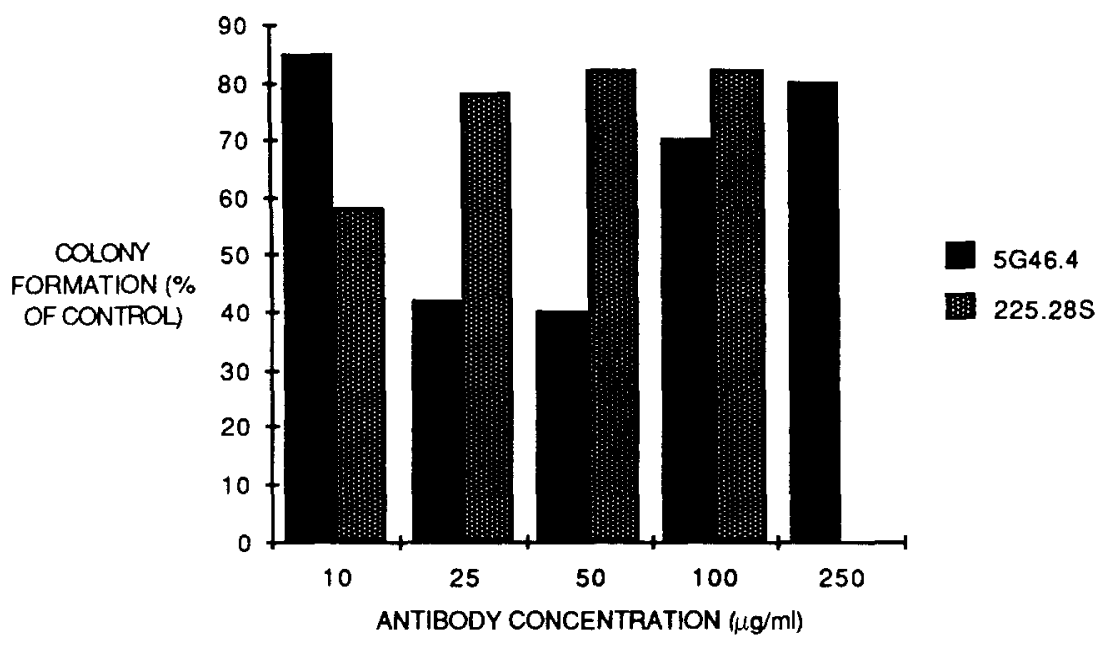

FIG. 2. Colony formation inhibition of MI OV Ca cells in the presence of 5 G6.4 (solid) or 225.28s (shaded). $225.28 \mathrm{~s}$ was not tested at $250 \mu \mathrm{g} / \mathrm{ml}$.

in vitro effect on $\mathrm{Ov} \mathrm{Ca}$ colony formation was inconsistent possibly due to a low level of antigen expression.

Figures 2 and 3 show the percentage of colony formation of the two different tumor cells used in relation to the different concentrations of 5G6.4 and 225.28s. The curves for both cell populations show a bell-shaped distribution for 5G6.4. The optimum concentration for best inhibition of tumor colony formation by $5 \mathrm{G} 6.4$ was $50 \mu \mathrm{g} / \mathrm{ml}$ for both cell populations. For MI OV colony formation was inhibited to $40-55 \%$ of control and for the malignant effusion it was $11 \%$ of control ( $\mathrm{P}<0.05$ compared to control using Student's $t$ test).

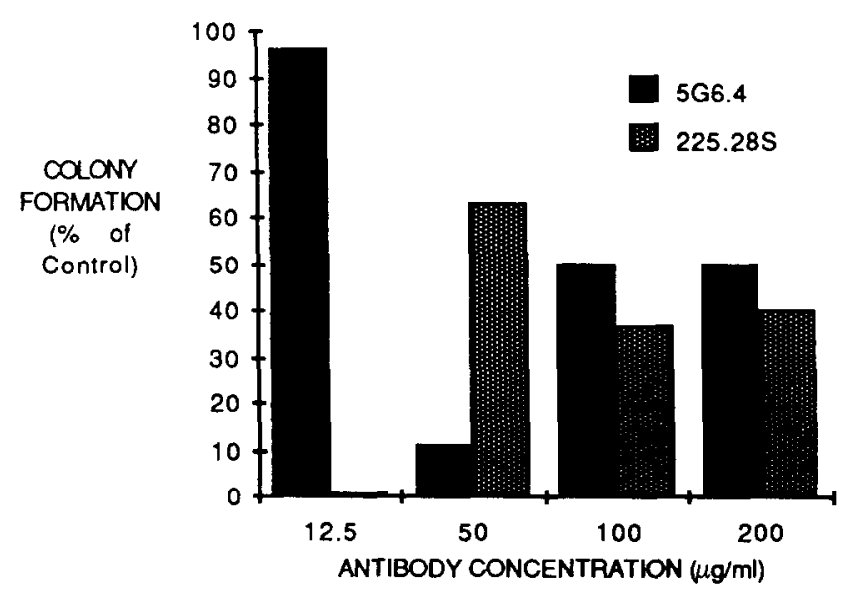

FIG. 3. Colony formation inhibition of TA Ov Ca cells in the presence of MAb 5 G6.4 (solid) or $225.28 \mathrm{~s}$ (shaded). $225.28 \mathrm{~s}$ was not tested at $12.5 \mu \mathrm{g} / \mathrm{ml}$. 


\section{DISCUSSION}

We report here the ability of a MAb, 5G6.4, to block the growth of human $\mathrm{Ov} \mathrm{Ca}$ cells in a tumor colony-forming assay in a nondose-related fashion. These results suggest that $5 \mathrm{G} 6.4$ may have potential immunotherapeutic usefulness but also indicate that the dose of antibody used for immunotherapy may be important. These results may be especially significant because of the nature of the colonyformation assay used. Growth of colonies measured in this assay is reportedly due to cells responsible for continued tumor growth and metastasis ("stem cells") [24].

Our results differ from those reported for several other MAbs capable of in vitro growth suppression. A MAb binding to transferrin receptor was previously shown to block cell growth in vitro, but in a dose-dependent fashion [13,25]. Prolonged exposure of melanoma cells to MAb R-24, an anti-GD3 ganglioside antibody, was shown to arrest cell growth, again in a dose-dependent fashion [14]. While the first assay looks at the growth inhibition of the whole malignant cell population, the second assay (used in our study) focuses on the growth inhibition of stem cells, which hypothetically are responsible for totipotential and continuous tumor growth.

The mechanism of growth inhibition by $5 \mathrm{G} 6.4$ remains to be determined. The unusual response to $5 \mathrm{G} 6.4$ (i.e., inhibition at 25 and $50 \mu \mathrm{g} / \mathrm{ml}$, lost at lower or higher concentrations of antibody) suggests some biological feedback. R-24, the anti-ganglioside GD3 MAb, appears to act through changes in membrane attachment sites [14]. Antitransferrin receptor may block uptake of essential nutrients [13,25]. Ov Ca cells have been reported to have growth factor receptors and to produce growth factors [26], both of which could act as targets for antibodies capable of growth inhibition. However, the $5 \mathrm{G} 6.4$ antigen does not resemble growth factors or receptors described previously $(13,25,26)$. Further, the antigen reactive with 5G6.4 appears to be a glycoprotein rather than a ganglioside or glycolipid, so the activity does not appear to be similar to R-24 (Wahl et al., unpublished).

These results suggest that MAb 5G6.4 may have a direct immunotherapeutic effect by blocking the growth of Ov Ca "stem cells." We are continuing the investigation of this activity and testing this $\mathrm{MAb}$ in vivo in a nude mouse model.

\section{ACKNOWLEDGMENTS}

The authors thank Drs. George Morley and James Roberts for obtaining cells, Ms. Claire Rogers for her expert technical help, and Ms. Paula Rust, M.A., and Dr. Hallie Kintner for advice and help with the manuscript.

\section{REFERENCES}

1. Epennetos, A. A., Hooker, G., Kraus, T., Snook, D., Bodmer, W. F., and Taylor-Papadimitriov, J. Antibody-guided irradiation of malignant ascites in ovarian cancer: A new therapeutic method possessing specificity against cancer cells, Obstet. Gynecol. 68, 71S (1986).

2. Kenemans, P., Verheijen, R. H. M., Leloux, A. M., and Poels, L. G. Prospects and applications of monoclonal antibodies in gynecological oncology, Eur. J. Obstet. Gynecol. Reprod. Biol. 19,340 (1985). 
3. Irie, R. F., and Morton, D. L. Regression of cutaneous metastatic melanoma by intra-lesional injection with human monoclonal antibody to ganglioside GD2, Proc. Natl. Acad. Sci. USA 83, 8694 (1986).

4. Sears, H. F., Herlyn, D., Steplewski, Z., and Koprowski, H. Effects of monoclonal antibody immunotherapy on patients with gastrointestinal adenocarcinoma, J. Biol. Response Modif. 3, 138, (1984).

5. Houghton, A. N., Mintzer, D., Cardon-Cardo, C., Welt, S., Fliegel, B., Vadhan, S., Carswell, E., Melamed, M. R., Oettgen, H. F., and Old, L. J. Mouse monoclonal IgG3 antibody detecting GD3 ganglioside: A phase I trial in patients with malignant melanoma, Proc. Natl. Acad. Sci. USA 82, 1242 (1985).

6. Miller, R. A., Maloney, D. G., Warnke, R., and Levy, R. Treatment of B cell lymphoma with monoclonal anti-idiotype antibody, N. Engl. J. Med. 306, 517 (1982).

7. Nadler, L. M., Stashenko, P., Hardy, R., Kaplan, W. P., Button, L. N., Kufe, D., Antman, K. H., and Schlossman, S. T. Serotherapy of a patient with a monoclonal antibody directed against a human lymphoma-associated antigen, Cancer Res. 40, 3147 (1980).

8. Miller, R. A., and Levy, R. Response of cutaneous T cell lymphoma to therapy with hybridoma monoclonal antibody, Lancet, 2, 226 (1981).

9. Steplewski, Z., Herlyn, D., Lubcek, M., Kimoto, Y., Herlyn, M., and Koprowski, H. Mechanisms of tumor growth inhibition, Hybridoma 5, (Suppl. 1), S59 (1986).

10. Cheresh, D. A., Honsik, C. J., Staffileno, L. K., Jung, G., and Reisfeld, R. A. Disialoganglioside GD3 on human melanoma serves as a relevant target antigen for monoclonal antibody-mediated tumor cytolysis, Proc. Natl. Acad. Sci. USA 82, 5155 (1985).

11. Hellstrom, I., Brankovan, V., and Hellstrom, K. E. Strong antitumor activities of IgG3 antibodies to a human melanoma-associated ganglioside, Proc. Natl. Acad. Sci. USA 82, 1499 (1985).

12. Schulz, G., Bumol, T. F., and Reisfeld, R. A. Monoclonal antibody-directed effector cells selectively lyse human melanoma cells in vitro and in vivo, Proc. Natl. Acad. Sci. USA 80, 5407 (1983).

13. Trowbridge, I. S., and Lopez, F. Monoclonal antibody to transferrin receptor blocks transferrin binding and inhibits human tumor cell growth in vitro, Proc. Natl. Acad. Sci. USA 79, 1175 (1982).

14. Dippold, W. G., Knuth, A., and Meyer zum Buschenfelde, K. H. Inhibition of human melanoma growth in vitro by monoclonal anti-GD3-ganglioside antibody, Cancer Res. 44, 806-810 (1984).

15. Ritz, J., Pesando, J. M., Sallan, S. E., Clavell, L. A., Notis-McConarty, J., Rosenthal, P., and Schlossman, S. F. Serotherapy of acute lymphoblastic leukemia with monoclonal antibodies, Blood 58, 141-152 (1981).

16. Wahl. R. L., Liebert, M., Biesman, B., Roberts, J., Jackson, G., Kronberg, S., and Laino, L. Production and characterization of a murine monoclonal antibody reactive with ovarian and other epithelial carcinomas, Proc. Amer. Assoc. Cancer Res. 27, 355 (1986).

17. Wahl, R. L., Geatti, O., Liebert, M., and Laino, L. Radioimmunoimaging and localization of human ovarian carcinoma xenografts, Radiology 157, (P), 217 (1985).

18. Welander, C. E., Natale, R. B., and Lewis, J. L. In vitro growth stimulation of ovarian cancer cells by zenogenic peritoneal macrophages, $J$. Natl. Cancer Inst. 69, 5 (1982).

19. Wilson, B. S., Ruberto, G., and Ferrone, S. Immunochemical characterization of a human high molecular weight-melanoma associated antigen identified with monoclonal antibodies, Cancer Immunol. Immunother. 14, 196 (1983).

20. Ey, P. L., Prowse, S. J., and Jenkins, C. R. Isolation of pure IgG1, IgG2a and IgG2b immunoglobulins from mouse serum using protein-A-sepharose, Immunochemistry 15, 429 (1978).

21. Bradford, M. A rapid and sensitive method for the quantitation of microgram quantities of protein utilizing the principle of protein-dye binding, Anal. Biochem. 72, 248 (1976).

22. Fraker, P. J., and Speck, J. C. Protein and cell membrane iodination with a sparingly soluble chloramide, 1,3,4,6-tetrachloro-s,6-diphenyl glycouril, Biochem. Biophys. Res. Commun. 80, 849 (1978).

23. Wahl, R. L., Liebert, M., Carey, J. E., and Jackson, G. Quality control of radiolabelled monoclonal antibodies: Immunologic and radiochemical, Cancer Drug Delivery 2, 236 (1985). 
24. Salmon, S. E., Hamburger, A. W., Soehlen, B., Durie, B. G. M., Alberts, D. S., and Moon, T. E. Quantitation of differential sensitivity of human-tumor stem cells to anticancer drugs, N. Engl. J. Med. 298, 1321 (1978).

25. Trowbridge, I. S., and Domingo, D. L. Anti-transferrin monoclonal antibody and toxin-antibody conjugates affect growth of human tumour cells, Nature (London) 294, 171 (1981).

26. Bauknecht, T., Kiechle, M., Bauer, G., and Siebers, J. W. Characterization of growth factors in human ovarian carcinoma, Cancer Res. 46, 2624 (1986). 